\title{
Surgical management of a conjunctival nevus with amniotic membrane transplantation
}

This article was published in the following Dove Press journal: International Medical Case Reports Journal

\section{Tobias Röck' Hans-Christian Bösmüller ${ }^{2}$ Karl Ulrich Bartz-Schmidt' Daniel Röck'}

'Centre for Ophthalmology, University of Tübingen, Tübingen, Germany; ${ }^{2}$ Institute of Pathology and Neuropathology, University of Tübingen, Tübingen, Germany
Correspondence: Tobias Röck Centre for Ophthalmology, University of Tübingen, Elfriede-Aulhorn-Straße 7, D-72076 Tübingen, Germany

$\mathrm{Tel}+49$ 707I 2988088

Email tobias.roeck@med.uni-tuebingen.de
Purpose: Nevi of the conjunctiva are usually benign pigmented tumorous lesions located in the bulbar conjunctiva. In most conjunctival nevus cases, the patient wants the lesion to be removed for cosmetic reasons, but excisional biopsies are best for lesions suspicious for malignancy. This case report illustrates the intraoperative surgical management, histological findings, and the course of healing in a conjunctival nevus patient.

Case report: A 26-year-old man was referred to our eye hospital with a large bulbar conjunctival nevus of the right eye. Upon examination, there was a large pigmented lesion with numerous small cysts present on the superior bulbar conjunctiva. The conjunctival tumor was resected, and an amniotic membrane transplantation was performed for the bulbar conjunctival reconstruction. The histopathological diagnosis suggested a conjunctival nevus. After the resection, a reduction in the inflammation and healing of the conjunctival lesion could be seen. The epithelialization of the bulbar conjunctiva over the amniotic membrane was complete 4 weeks after the resection. At the 6-month follow-up, there was no sign of recurrence or any postoperative complications. Conclusion: A surgical excision combined with reconstruction via amniotic membrane transplantation is effective and economical for the treatment of large conjunctival lesions.

Keywords: conjunctival nevus, reconstructive surgical procedures, amniotic membrane transplantation, ocular surface reconstruction

\section{Introduction}

Pigmented conjunctival lesions exhibit a wide variety of appearances, and the differential diagnoses of these include nevi, melanoses, and malignant melanomas. ${ }^{1} \mathrm{~A}$ nevus that shows signs of enlargement, an irregular shape, and variegated color may develop into a malignant melanoma. ${ }^{2}$

Amniotic membrane transplantation (AMT) can be used to reconstruct conjunctival defects created by the surgical removal of such pigmented tumors. The first AMT was performed therapeutically in humans 108 years ago, in 1910, as a skin substitute for treating an open wound. ${ }^{3}$ Nowadays, the widespread use of AMTs has likely been influenced by the easy processing and cryopreservation techniques, which were introduced 20 years ago. ${ }^{4}$

In recent years, AMTs have been used increasingly and successfully to treat, manage, and reconstruct various types of ophthalmic conditions, which include particularly persistent corneal epithelial defects, corneal ulcers, and conjunctival defects after the resection of lesions. ${ }^{5}$ The amniotic membrane (AM) has wide clinical applications in various fields of medicine, because it contains abundant growth factors and 
anti-inflammatory proteins, promotes epithelialization, inhibits fibrosis, and suppresses inflammation and bacterial growth. ${ }^{6-8}$ AMs have already been used as biological dressings in abdominal surgery, genital reconstruction, oral and periodontal procedures, and plastic surgery. ${ }^{9-11}$

In this case report, we illustrate the case of a huge conjunctival nevus requiring an AMT to reconstruct the ocular surface after the nevus resection.

\section{Case report}

A 26-year-old man was referred to our eye hospital in July 2017 with a bulbar conjunctival lesion $(8 \mathrm{~mm} \times 6 \mathrm{~mm})$ of the right eye. Upon examination, a large pigmented lesion with numerous small cysts was present on the superior bulbar conjunctiva (Figure 1). The initial clinical findings showed a tumor, which appeared to be smooth, soft, and mobile.

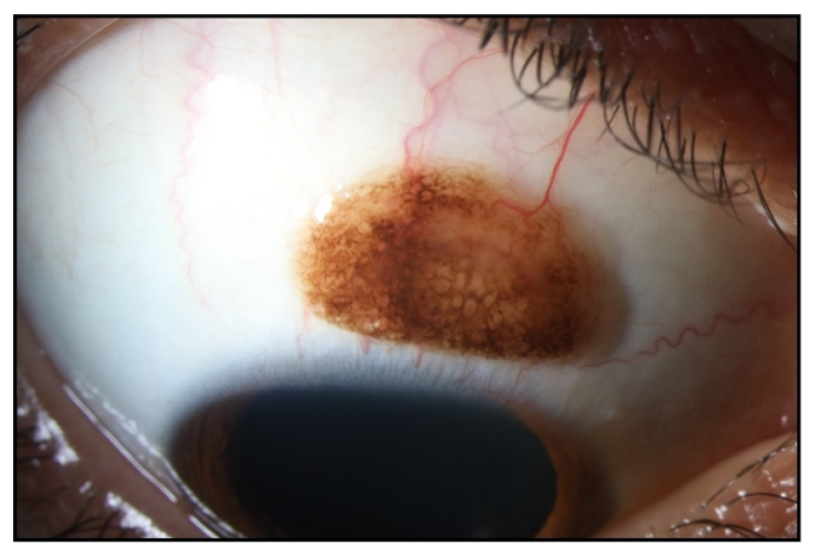

Figure I Initial slit-lamp image showing an $8 \mathrm{~mm} \times 6 \mathrm{~mm}$ large pigmented lesion with numerous small cysts in the superior bulbar conjunctiva of the right eye.
For this case, an AMT using the inlay technique was applied, and the surgery is shown in Figure 2. The conjunctival tumor was resected using a wide excisional biopsy with a tumor safety distance of $2.0 \mathrm{~mm}$. Then, the resection was performed using the "no-touch" technique. ${ }^{12}$ Later, the conjunctival defect was reconstructed using an AM, which was placed with the stromal side facing down toward the defect. It was secured to the surrounding conjunctiva by five interrupted 9-0 Vicryl sutures.

A topical corticosteroid (dexamethasone), antibiotic eye drops $(0.5 \%$ moxifloxacin hydrochloride ophthalmic solution), and artificial tears were used postoperatively four times a day over a 2 -week period. Then, the corticosteroid eye drops were reduced by one drop each week, while the artificial tears were still applied four times a day for 8 weeks.

Figure 3 shows the histopathological slides of the nevus stained with hematoxylin and eosin $(\times 20$ and $\times 50$ magnification), on which numerous nests of nevus cells containing abundant melanin pigment could be seen under the conjunctival epithelium. Figure 4 shows this eye's course of healing over time, in which a reduction in the inflammation and healing of the conjunctival defect could be seen. The conjunctival epithelium grew over the AM graft; therefore, the AM became partly integrated into the host tissue. In addition, the conjunctival inflammation decreased quickly. Six months after the resection and AMT, a slit-lamp examination revealed stable findings.

Written informed consent of the patient was obtained to publish this case report. In addition, this case report was approved by the institutional review board of the University
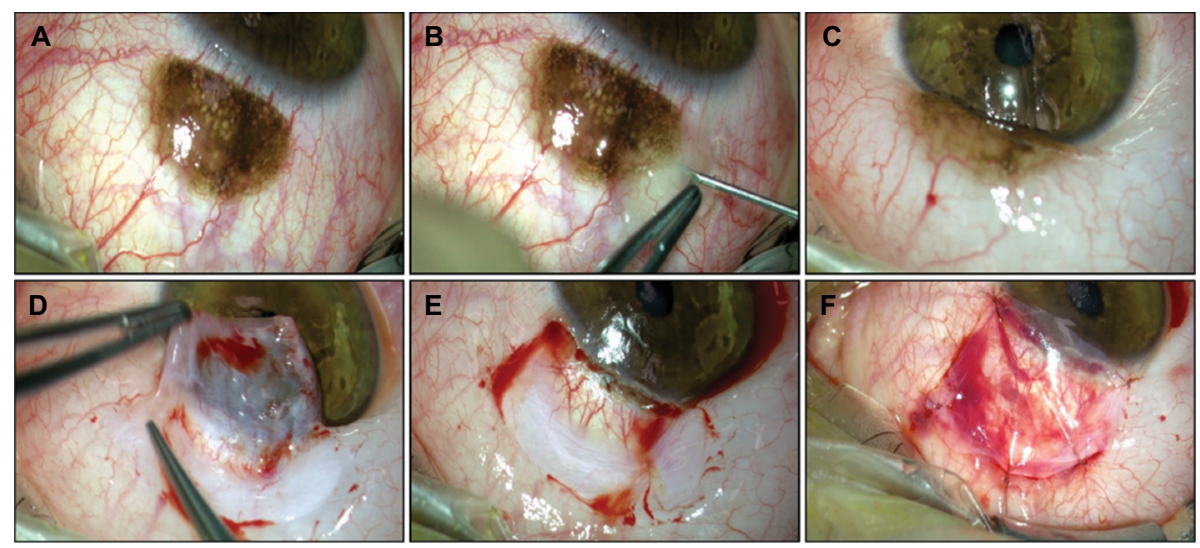

Figure 2 (A) Color photograph of the surgical video after the application of topical anesthesia (five drops of a single dose of $0.4 \%$ oxybuprocaine hydrochloride). (B and C) Subconjunctival anesthesia with $2 \%$ mepivacaine. (D) The conjunctival tumor was resected using a wide excisional biopsy with a tumor safety distance of 2.0 mm. The resection was performed using the "no-touch" technique. (E) The $12 \mathrm{~mm} \times 10 \mathrm{~mm}$ conjunctival defect. (F) The AM was placed with the stromal side facing down toward the defect. The AM was secured to the surrounding conjunctiva by five interrupted 9-0 Vicryl sutures.

Abbreviation: AM, amniotic membrane. 


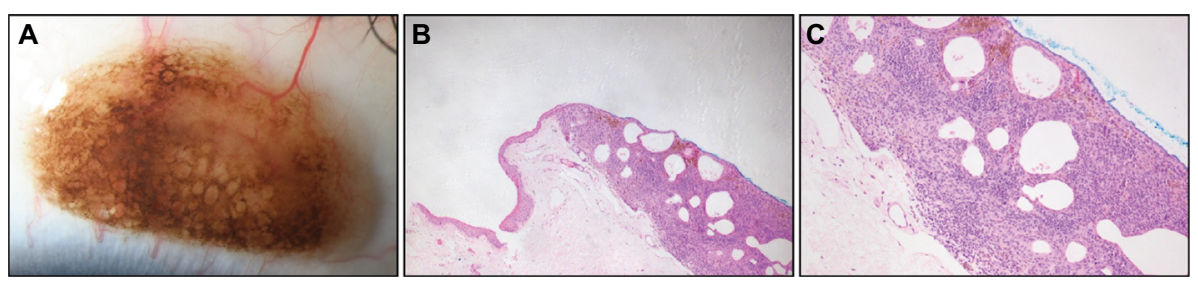

Figure 3 (A) Magnified slit-lamp image showing the pigmented lesion with numerous small cysts. (B) Histopathological slide of the tumor stained with H\&E, $\times 20$. (C) Histopathological slide of the tumor stained with $\mathrm{H} \& \mathrm{E}, \times 50$. Numerous nests of nevus cells containing abundant melanin pigment can be seen under the conjunctival epithelium.

Abbreviation: H\&E, hematoxylin and eosin
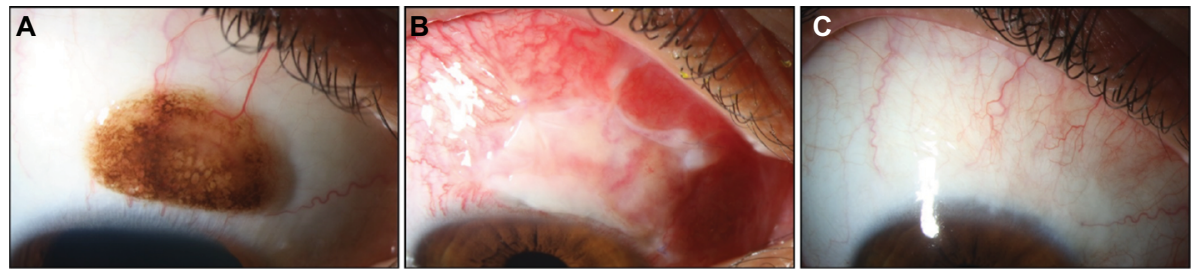

Figure 4 Slit-lamp images showing the course of healing over time.

Notes: (A) Slit-lamp image showing the large pigmented lesion before surgery. (B) Seven days after the resection and AMT. (C) A slit-lamp examination revealed stable findings 6 months after surgery. The AM has been partly integrated into the host tissue, while the ocular surface inflammation and corneal vascularization have decreased. Abbreviations: AM, amniotic membrane; AMT, AM transplantation.

of Tübingen and adhered to the tenets of the Declaration of Helsinki.

\section{Discussion}

Regular self-examinations in which a patient recognizes a suspect lesion have been shown to be important for the prevention and early detection of melanomas. ${ }^{13}$ To help patients identify suspect lesions, the "ABCDE rule" is often recommended, which was first introduced in 1985 as the "ABCD rule,"14 and later expanded to ABCDE in 2004. ${ }^{15}$ Suspect lesions that fulfill some or even one of the ABCDE criteria can be included in a biopsy and undergo a histopathological evaluation. The ABCDE rule includes several clinical melanoma features: Asymmetry, Border irregularity, Color variation, Diameter greater than $6 \mathrm{~mm}$, and Evolution (changes in size, shape, or elevation). Soltani-Arabshahi et $\mathrm{al}^{16}$ reported that their data from a total of 2,643 biopsy specimens from suspect lesions supported the 6-mm criterion in the ABCDE rule.

In our case, the bulbar conjunctival pigmented lesion was $8 \mathrm{~mm} \times 6 \mathrm{~mm}$ in size, with a color variation, and the size progression was known. Together with the patient, we decided to remove the suspect lesion using a wide excisional biopsy with a safety distance of $2.0 \mathrm{~mm}$. The surgical removal of such a large conjunctival lesion can be a significant therapeutic challenge. Unfortunately, complications caused by the resection of conjunctival lesions are frequently seen, including symblepharon, scarring, and a partial or total limbal stem cell deficiency. ${ }^{17,18}$ Moreover, conjunctival scarring could lead to reduced motility of the globe, resulting in diplopia. The main concern for the surgeon in these challenging situations is to find a suitable graft for reconstructing the resected area to avoid the complications listed earlier.

The effectiveness of AMTs was sufficiently indicated as supplement of the collagen layer and basement membrane. ${ }^{5}$ The AM does not supply the epithelial cells. Thus, AM grafting should be distinguished from epithelial transplantation known as conjunctival and mucosal graft. Conjunctival and mucosal grafts have been used for more than a century in ophthalmic reconstruction. In the recent 2 decades, the assessment of these techniques has changed because alternative techniques, such as AMTs, have extended the therapeutic options. Among the various alternatives and, in part, newer techniques, conjunctival and mucosal grafting is still an upto-date and suitable procedure for the replacement of the conjunctiva. Its advantages include the easy availability of the grafts, fast and cheap grafting, and high graft stability and toughness. ${ }^{18,19}$

Conjunctival, mucosal, and AM grafts can be used for the reconstruction of large conjunctival defects, and these 
additional possibilities for the management of large conjunctival gaps should not be forgotten. However, the AM has several superior features over mucosal grafts. In previous studies, AMTs have been found to be good choices for the reconstruction and restoration of persistent epithelial defects of the cornea and corneal ulcers as well as conjunctival defects. ${ }^{20-22}$ Moreover, an AMT can help to maintain a normal conjunctival phenotype and has cosmetic benefits over buccal or mucosal grafts, which result in a nonconjunctival epithelial morphology. ${ }^{23-25}$ The AM shows advantages for many reasons, including its rich source of stem cells, which support and promote conjunctival and corneal epithelialization and healing, its immunogenicity, and its reductions in inflammation, immune rejection, vascularization, scarring, and pain. ${ }^{6-8,26}$

However, small-size conjunctival tumor excisions do not need AM grafting because conjunctival wound healing is secured and there are low risks of persistent epithelial defect and fibrotic scaring. Tenon's capsules should not be resected in such case, which contribute to reepithelialization of the conjunctiva. Conjunctiva does not form severe scars when Tenon's capsules are preserved. Another possibility would be preparing a rotational conjunctival flap with nonabsorbable material suture, a local free conjunctival flap, and/or pedunculated flap to treat conjunctival defect. AMT should be applied in selected patients with temporally huge conjunctival defects during resection.

In our case, we decided to reconstruct the vast conjunctival defect using an AMT, and this eye's course of healing was quick, without scarring or complications. As shown by our results, an AMT can be used very easily and successfully to reconstruct large conjunctival defects. AMs are widely available, economical, and easy to manipulate, process, and store.

\section{Conclusion}

A surgical excision combined with an AMT reconstruction is effective and economical for the treatment of large conjunctival lesions. An AMT should be considered as a secure and easy option in reconstructive and regenerative ophthalmology.

\section{Acknowledgment}

This case report was supported by the Deutsche Forschungsgemeinschaft and the Open Access Publishing Fund of the University of Tübingen.

\section{Disclosure}

The authors report no conflicts of interest in this work.

\section{References}

1. Liesegang TJ. Pigmented conjunctival and scleral lesions. Mayo Clin Proc. 1994;69(2):151-161.

2. Goldstein AM, Tucker MA. Dysplastic nevi and melanoma. Cancer Epidemiol Biomarkers Prev. 2013;22(4):528-532.

3. Davis JS. Skin transplantation. Johns Hopkins Hosp Rep. 1910;15:307-396.

4. Lee S-H, Tseng SC. Amniotic membrane transplantation for persistent epithelial defects with ulceration. Am J Ophthalmol. 1997;123(3):303-312.

5. Röck T, Bartz-Schmidt KU, Landenberger J, Bramkamp M, Röck D. Amniotic membrane transplantation in reconstructive and regenerative ophthalmology. Ann Transplant. 2018;23:160-165.

6. McQuilling JP, Vines JB, Mowry KC. In vitro assessment of a novel, hypothermically stored amniotic membrane for use in a chronic wound environment. Int Wound J. 2017;14(6):993-1005.

7. Tseng SC, Espana EM, Kawakita T, et al. How does amniotic membrane work? Ocul Surf. 2004;2(3):177-187.

8. Adzick NS, Lorenz HP. Cells, matrix, growth factors, and the surgeon. The biology of scarless fetal wound repair. Ann Surg. 1994;220(1):10-18.

9. Mohan R, Bajaj A, Gundappa M. Human amnion membrane: potential applications in oral and periodontal field. J Int Soc Prev Community Dent. 2017;7(1):15-21.

10. Jirsova K, Jones GLA. Amniotic membrane in ophthalmology: properties, preparation, storage and indications for grafting - a review. Cell Tissue Bank. 2017;18(2):193-204.

11. Fairbairn NG, Randolph MA, Redmond RW. The clinical applications of human amnion in plastic surgery. J Plast Reconstr Aesthet Surg. 2014;67(5):662-675.

12. Shields JA, Shields CL, De Potter P. Surgical management of conjunctival tumors: the 1994 Lynn B. McMahan Lecture. Arch Ophthalmol. 1997;115(6):808-815.

13. Titus LJ, Clough-Gorr K, Mackenzie TA, et al. Recent skin selfexamination and doctor visits in relation to melanoma risk and tumour depth. Br J Dermatol. 2013;168(3):571-576.

14. Friedman RJ, Rigel DS, Kopf AW. Early detection of malignant melanoma: the role of physician examination and self-examination of the skin. CA Cancer J Clin. 1985;35(3):130-151.

15. Abbasi NR, Shaw HM, Rigel DS, et al. Early diagnosis of cutaneous melanoma: revisiting the ABCD criteria. JAMA. 2004;292(22):2771-2776.

16. Soltani-Arabshahi R, Sweeney C, Jones B, Florell SR, Hu N, Grossman D. Predictive value of biopsy specimens suspicious for melanoma: support for 6-mm criterion in the ABCD rule. J Am Acad Dermatol. 2015;72(3):412-418.

17. Celik T, Katircioglu YA, Singar E, et al. Clinical outcomes of amniotic membrane transplantation in patients with corneal and conjunctival disorders. Semin Ophthalmol. 2013;28(1):41-45.

18. Yao YF, Qiu WY, Zhang YM, Tseng SC. Mitomycin C, amniotic membrane transplantation and limbal conjunctival autograft for treating multirecurrent pterygia with symblepharon and motility restriction. Graefes Arch Clin Exp Ophthalmol. 2006;244(2):232-236.

19. Mai C, Bertelmann E. Oral mucosal grafts: old technique in new light. Ophthalmic Res. 2013;50(2):91-98.

20. Tseng SC. Amniotic membrane transplantation for ocular surface reconstruction. Biosci Rep. 2001;21:481-489.

21. Meller D, Pauklin M, Thomasen H, Westekemper H, Steuhl KP. Amniotic membrane transplantation in the human eye. Dtsch Arztebl Int. 2011;108(14):243-248.

22. Paridaens D, Beekhuis H, van Den Bosch W, Remeyer L, Melles G. Amniotic membrane transplantation in the management of conjunctival malignant melanoma and primary acquired melanosis with atypia. $\mathrm{Br}$ J Ophthalmol. 2001;85(6):658-661.

23. Ahmad MS, Frank GS, Hink EM, Palestine AG, Gregory DG, McCourt EA. Amniotic membrane transplants in the pediatric population. $J$ AAPOS. 2017;21(3):215-218.

24. Prabhasawat P, Tesavibul N. Preserved amniotic membrane transplantation for conjunctival surface reconstruction. Cell Tissue Bank. 2001;2(1):31-39. 
25. Asoklis RS, Damijonaityte A, Butkiene L, et al. Ocular surface reconstruction using amniotic membrane following excision of conjunctival and limbal tumors. Eur J Ophthalmol. 2011;21(5):552-558.
26. Kim EY, Lee KB, Kim MK. The potential of mesenchymal stem cells derived from amniotic membrane and amniotic fluid for neuronal regenerative therapy. BMB Rep. 2014;47(3):135-140.

\section{Publish your work in this journal}

The International Medical Case Reports Journal is an international, peer-reviewed open-access journal publishing original case reports from all medical specialties. Previously unpublished medical posters are also accepted relating to any area of clinical or preclinical science. Submissions should not normally exceed 2,000 words or
4 published pages including figures, diagrams and references. The manuscript management system is completely online and includes a very quick and fair peer-review system, which is all easy to use. Visit http://www.dovepress.com/testimonials.php to read real quotes from published authors. 